\title{
PESQUISA EM PSICANÁLISE: DA QUALIFICAÇÃO DESQUALIFICANTE À SUBVERSÃO
}

Roberto Calazans e Tiago Iwasawa Neves

\author{
Roberto Calazans \\ Doutor em Teoria \\ Psicanalítica pela \\ Universidade \\ Federal do Rio de \\ Janeiro. Professor \\ do Programa de \\ Pós-Graduação \\ em Psicologia \\ da Universidade \\ Federal de São João \\ del Rei. \\ Tiago Iwasawa Neves \\ Mestre em \\ Psicologia pela \\ Universidade \\ Federal de Minas \\ Gerais. Professor \\ Assistente da \\ Faculdade Pitágoras \\ - Campus Ipatinga. \\ Membro do \\ Centro de Estudos \\ e Pesquisa em \\ Psicanálise - Cepp \\ Vale do Aço.
}

RESUMO: Trata-se de apresentar notas para uma discussão sobre o método de pesquisa em psicanálise. Entre a psicanálise e a ciência há uma relação de compatibilidade lógica que se refere ao uso de uma qualificação que desqualifica o sentido habitual dos conceitos, produzindo assim um novo conceito pela via de articulações até então impossíveis. Esse trabalho é chamado pela epistemologia histórica de qualificação desqualificante, e por Lacan, de subversão. A articulação destes dois conceitos atesta a compatibilidade entre o modo de pesquisar em ciência e em psicanálise.

Palavras-chave: psicanálise, pesquisa, método, subversão.

ABSTRACT: Psychoanalysis research: from disqualifying qualification to subversion. This article presents observations for a discussion on the research method in psychoanalysis. Between psychoanalysis and science there is a relationship of logical compatibility that refers to the use of a qualification that disqualifies the usual meaning of the concepts, thus producing a new concept by means of articulations that were previously impossible. This paper is called by the historical epistemology of qualification, disqualifying, and for Lacan, subversion. The articulation of these two concepts certifies the compatibility between the way of researching in science and in psychoanalysis.

Keywords: psychoanalysis, research, method, subversion.

\section{INTRODUÇÃ̃O}

Jacques-Alain Miller (2000a) aponta que a primeira fase do ensino de Lacan é pautada por uma crítica da forma lógica do saber científico, "na medida em que a ciência é aquela que desata esse saber da verdade, e precisamente da verdade do sujeito" (p.30). Haveria assim, na ciência uma sutura da 
divisão do sujeito. É em relação a essa disjunção entre saber e verdade que Lacan irá afirmar que a ciência recalca a verdade, e "que cabe a outra disciplina — que seria a psicanálise — a se instalar no campo da verdade” (p.31). Miller faz essa notação tomando por base o texto lacaniano Subversão do sujeito e dialética do desejo (1960/1998, p.813). A despeito da crítica de Lacan em relação à ciência, podemos notar que nessa mesma crítica está implícito que a psicanálise só pode surgir como um dos efeitos do advento do discurso científico. Afinal, como não ler isso no aforismo encontrado em Do sujeito enfim em questão: “o fato de a psicanálise haver nascido da ciência é patente. Que pudesse ter surgido de outro campo, é inconcebível" (LACAN, 1966/1998, p.232), e que possa ter nascido de outro discurso, um absurdo. Nessa frase encontramos, por um lado, a crítica - a psicanálise nasce da ciência devido ao fato de esta nada querer saber da verdade e do sujeito - e, por outro, a homologia entre a psicanálise e a ciência — o absurdo de que a psicanálise possa ser de outro mundo que não o científico, isto é: a psicanálise só tem valor em um mundo em que o sentido foi abolido pelo saber científico.

Cremos que essa introdução se torna necessária a partir do momento que se coloca a questão da pesquisa em psicanálise, principalmente a feita nas universidades. Será que podemos confundir o discurso da universidade com o discurso da ciência? Não. O discurso da ciência surge apenas após a matematização da física. Já o discurso universitário aparece na Idade Média. O discurso da ciência é na verdade antinômico ao discurso universitário - este se caracteriza por ser da ordem do saber adquirido, enquanto o discurso da ciência se caracteriza por ser da ordem da problematização do saber. Desse modo, não podemos deixar de considerar que se há homologia da psicanálise com o discurso científico é porque ela só pode surgir em um mundo afetado pelo advento da atividade científica: sem hierarquia, sem qualidades e infinito. A psicanálise trata justamente daquilo que é deixado de lado pelo discurso da ciência: o sujeito.

Mas não se trata de mera homologia. Podemos dizer, nos valendo de JeanClaude Milner (1996), que a relação entre a psicanálise e a ciência é da ordem de uma compatibilidade lógica. Se há compatibilidade entre os dois discursos, é por não querer outro modo de encaminhamento que não siga o aspecto formal, que coloque uma lógica para funcionar e avaliar o que ela produz de impasse, e que não busque um fora do discurso para avaliar uma formação discursiva. Ou seja, essa compatibilidade lógica não se dá tão somente por tratar dos efeitos do discurso da ciência; se dá também por não considerar o sujeito como um ser dotado de qualidades, mas como um efeito de uma articulação de significantes que não tem sentido em si mesma; e por considerar seu problema em função do sentido que especifica um campo de ação, sem querer subordinar-se à ou subordinar a ciência. Ou seja, a compatibilidade lógica é da ordem do modo 
de encaminhar as questões, em que são ressaltados os cortes epistemológicos, os impasses e a criação de novos conceitos que determinam novos recortes.

No entanto, é na maneira de pensar esses recortes e esses impasses que se coloca a questão da investigação em psicanálise. Se a psicanálise é compatível com a atividade científica, então sua pesquisa também deve ser compatível. Partiremos de um resumo histórico da afiliação do modo de pesquisar que podemos denominar com Canguilhem como o trabalho de um conceito, no qual entra em jogo a busca de impasses para que uma ruptura possa advir. Sobre este trabalho do conceito, Gaston Bachelard (2004) afirmou que o mesmo se orienta a partir de operadores específicos: deformação e retificação. Como consequências, nós temos, na epistemologia, o que o epistemólogo Dominique Lecourt chama de qualificação desqualificante (1969, p.40); e na psicanálise, o que Jacques Lacan chama de subversão. É dessa configuração que iremos extrair as consequências para a investigação em psicanálise

\section{EPISTEMOLOGIA}

Buscamos aqui uma orientação que possa ser considerada metodológica para a pesquisa em psicanálise. Acreditamos que esta orientação deva estar conforme com a tese da compatibilidade lógica entre o pensamento científico e o pensamento psicanalítico. Esta tese só se sustenta se seguirmos uma epistemologia específica que não pretenda impor à ciência um modelo geral de métodos ou de critérios de validação, mas que visa integrar seu pensamento em torno da autonomia das regiões epistemológicas, a saber, a epistemologia histórica de Gaston Bachelard.

Segundo Bachelard (1996), a objetividade alcançada pela atividade científica moderna não é da ordem da revelação de objetos. Para a epistemologia histórica, não há conhecimento por acúmulo de informações sobre um objeto. Afirmar um objeto, na ciência, é ultrapassar o dado imediato e sensível. Trata-se, a partir de então, de produzir um real a partir de uma inter-relação conceitual, e não a partir de esquemas racionais prévios e de uma realidade fenomenal. "Essa necessidade de sentir o objeto, esse apetite dos objetos, essa curiosidade indeterminada ainda não correspondem — sob nenhum título - a um estado de Espírito Científico” (BACHELARD, 1996, p.294).

Dessa forma, os objetos científicos são produzidos a partir de uma objetivação, e não a partir de um imediatismo da experiência. O real não pode ser mais considerado como uma categoria imutável e não-contraditória. Por esta razão é que também não podemos pensar este trabalho de produção de um real como fruto de uma razão fixa e fechada. Robert Blanché (1983) afirmou que é contra esta tese que se coloca a lógica da ciência, uma vez que esta última obriga a colocar em questão a ideia de uma universalidade e imutabilidade do espírito (p.18). 
A epistemologia histórica se posiciona na contramão do racionalismo clássico, pois admitir uma razão que não se deforma ou retifica implica necessariamente em considerarmos, por exemplo, que o objeto da física seja o mesmo desde sempre. "As ciências que são, por excelência, fruto da razão, foram, por caminhos diversos, levadas a contestar a validade absoluta dos princípios que se tinha até então julgados constitutivos da razão” (BLANCHÉ, 1983, p.20-22).

Não é só o racionalismo clássico que perde seu sentido. Como consequência do trabalho de produção dos objetos científicos, o empirismo tradicional perde também o seu: a realidade não é mais dada, e sim produzida. Com efeito, a deformação e retificação dos conceitos, é o modo como a ciência moderna opera a produção de um real. Deformar, retificar, buscar a variação e não a variedade, estas características conduzem a ciência a estabelecer uma lógica que não pode ser reduzida pela busca de uma certeza. Diríamos, a partir de Dominique Lecourt (1969), que o axioma fundamental da epistemologia histórica é a positividade do erro. Ora, somente um aparato conceitual pode estabelecer as coordenadas para se pensar uma realidade. Então, o erro nada mais é do que uma oportunidade de deformar um conhecimento já estabelecido, isto é, um estágio conceitual que gera impasses para a aplicação do conceito na experiência. É o trabalho de articulação conceitual que deve ser validado. O erro é mais operativo para o Espírito Científico; uma novidade obriga a colocar em questão um conhecimento anterior.

O método científico é, portanto, um método de retificação e deformação. Esta questão é essencial para as ciências humanas, pois sua necessidade de se manter com status de ciência sempre dependeu do encontro do método adequado. Por isso é necessário, em primeiro lugar, dizer que um método é, etimologicamente falando, abrir caminhos. Quando se fala de método podemos então definir que a nossa orientação é metodológica, pois permite abrir caminhos ou traçar novas vias no real. No entanto, quando estamos às voltas com as ciências humanas, temos uma mutação da questão: o método tem que ser científico, e quando o método precisa estar às voltas com este qualificativo, é por que alguma coisa já não funciona: ou o problema já não é científico, ou o método é uma tentativa de conferir objetividade. Geralmente esta questão é tratada em termos não de traçar um caminho no real, mas em termos do método ser uma maneira de se conseguir atingir uma realidade dada. Em relação à psicanálise, podemos parafrasear Jacques-Alain Miller (1998, p.232) e dizer que na pesquisa em psicanálise nós não temos um método padrão - mas sim princípios norteadores para a pesquisa. Estes princípios são derivados não de sua subordinação à ciência, mas de sua compatibilidade a ela.

Deste modo, acreditamos que podemos definir como orientação de pesquisa o que Canguilhem chama de trabalho de um conceito: 
“trabalhar um conceito é fazer variar sua extensão e compreensão, generalizá-lo mediante a importação de traços de exceção, exportá-lo para fora de sua região de origem, tomá-lo como modelo ou, inversamente, fornecer-lhe um, em resumo, dar-lhe progressivamente a função de uma forma” (CANGUILHEM, 1975, p.256)

Este se caracteriza pela extensão do conceito até seus limites: a análise dos efeitos da relação deste conceito com outros, o teste, enfim, da capacidade deste conceito ser fecundo. Esta posição parte de uma epistemologia específica, que demonstra que não há possibilidade de falar de um fenômeno sem a articulação conceitual. É a epistemologia histórica que tem sua origem nos trabalhos de Leon Brunschiviq - o racionalismo construtivo - e teve frutos nos trabalhos de epistemólogos importantes, tais como: Gaston Bachelard (epistemologia da física e da química), Robert Blanché (trabalhos sobre lógica e epistemologia da física), George Canguilhem (epistemologia da biologia), François Dagognet (epistemologia da biologia), François Jacob (epistemologia da genética), Alexandre Koyré (história da ciência), Jean Cavaillès (epistemologia da matemática), Houria Sinaceur (epistemologia da matemática), Dominique Lecourt (história da epistemologia). O que caracteriza estas epistemologias é a assunção de autonomia dos campos de problemas para avaliá-los e o acompanhamento que se faz do trabalho científico sem a pretensão do que se coloca do exterior para julgá-lo. Esta posição traz como consequência a assunção do aspecto formal e do trabalho do conceito a partir de suas variações para produzir uma rede cerrada que trace caminhos no real.

Isto apenas para falar da importância desta orientação dentro do campo da ciência. Se considerarmos o campo de problemas da ordem do sujeito, vemos como esta orientação influenciou diretamente os trabalhos de Martial Guéroult sobre Descartes, de Pierre Aubenque sobre Aristóteles, de Claude Lévi-Strauss em antropologia, Roman Jakobson em linguística, Michel Foucault em sua arqueologia do saber e genealogia do poder, Louis Althusser sobre o marxismo, Roland Barthes no que diz respeito à semiologia, Paul Veyne e Jean Pierre Vernant na história, Jacques Lacan em psicanálise. O nome que podemos dar a esta compatibilidade lógica de Espírito Científico: mesmo que estes autores não estejam às voltas com problemas que possam ser tratados por uma definição operatória, eles não podem ficar indiferentes ao real que se produz em uma ciência. A partir de então, proceder de outra maneira é colocar em jogo uma lógica de pensamento que não é própria ao mundo em que a ciência é possível.

Se dissermos que a orientação metodológica é o trabalho de um conceito, é por considerarmos esta denominação, cunhada por Canguilhem, a que melhor expressa o trabalho desta afiliação de pensamento. E também que não é gratuito, uma vez que colocamos nosso trabalho sob a orientação da epistemologia histórica 
de Gaston Bachelard, que esta definição de Canguilhem seja feita em um texto em sua homenagem. Mas ainda há outra razão: é desta afiliação que surgiu, na década de 1960, o Círculo de Epistemologia da École Normal Superier, que se articulava em torno da revista Cahiers pour l'analyse e de onde saíram alguns dos nomes mais preeminentes da psicanálise atual: Jacques-Alain Miller, Alain Gorischard, Éric Laurent, Colete Soler, François Regnault, Gerard Miller, Serge Cottet. Todos estes autores, mesmo que hoje tenham divergências teóricas, se agruparam também em torno do projeto lacaniano de retorno a Freud. Este projeto tinha — e ainda tem - por alvo trazer de volta à psicanálise não o que Freud havia dito, mas o que Freud havia pensado e produzido em termos de experiência, que podemos chamar de psicanálise: o seu poder crítico e clínico e a sua produção conceitual em que se admite o poder do artifício, em detrimento do realismo. É uma das maneiras de se conceber a pesquisa e o encaminhamento de uma questão por compartilhar dos seguintes pressupostos: o de que um conceito só pode ser analisado em função do sentido de um problema; que um conceito não existe sozinho, mas sempre em correlação a outros; e de que não faz sentido pensar em um objeto sem nenhuma operação de pensamento, pois seria recair em um realismo absurdo. E de que é em função de uma discussão conceitual que se consegue a estruturação de uma experiência. Pode-se concordar com isso ou não, mas não se pode deixar de dizer que é um procedimento para dar encaminhamento às questões que são colocadas. E, digam o que disserem, uma questão, como nos demonstra Bachelard, não se coloca por si mesma, mas ao contrário, "o que caracteriza o espírito científico é esse sentido do problema” (1996, p.18). E quando encontramos algo que coloca uma rede de conceitos em questão é sempre em função desta rede de relações que este 'a mais' é considerado.

Como consequência, há o que podemos denominar como uma orientação metodológica do não-sentido: não-sentido das relações conceituais que podem, a partir daí, produzir uma unidade de sentido; mas não-sentido também do real que se produzirá, possibilitando o questionamento e exigindo uma nova rede de conceitos para que se possa dar conta deste excesso. Como afirma Bachelard: “a ciência é uma luz que sempre projeta algumas sombras” (1996, p.17). Esta articulação é própria ao pensamento científico? Diríamos que sim, com base nos trabalhos de Koyré. Segundo este autor, uma das características do pensamento moderno, que irá diferenciá-lo do pensamento antigo, é a afirmação de um trabalho sem qualidades para produzir um fenômeno objetivo. Dada esta nãoqualidade, não precisamos mais buscar um sentido prévio ao trabalho, nem nos dedicarmos a dotar de qualidades teóricas uma realidade prévia. Um fenômeno só se torna objetivo a partir do momento que se tira dele todas as qualidades e que se dê sua ordem de produção. É esta ordem de produção, que não passa de uma relação conceitual, que permite que se possa fazer uma ciência e transmitir 
algum ensinamento. É sobre ela também que se podem fazer as variações que poderão produzir novos fenômenos que questionarão as teorias antigas. Como afirma Bachelard: "o homem do mundo científico deseja saber, mas para melhor questionar" (1996, p.21).

Desta falta de qualidades podemos depreender outras duas características do mundo moderno: a falta de hierarquia no campo do saber e a infinitude. Destas três características podemos extrair uma conclusão: um pensamento faz parte do mundo científico quando ele coloca uma nova lógica para funcionar e explica o real pelo impossível. Vejamos como: se um pensamento não tem qualidade ou sentido originário, se o sentido é fruto da articulação conceitual, não faz mais sentido falar em uma hierarquia de saberes, em que um pode ser dito melhor do que outro. Para que se possa fazer isso seria necessário ter uma continuidade dos objetos a serem tratados, ou um mesmo procedimento intelectual que colocaria todos os problemas em um mesmo patamar. Ora, se os objetos surgem de uma rede de conceitos específicos em função de um problema específico, não podemos mais falar em realidade dada ou em um esquema a priori de entendimento. Temos assim o que Gaston Bachelard irá denominar de racionalismo regional (1977a, p.121), exemplificado por ele com a questão dos fundamentos da matemática: é um problema entre outros na matemática; não é necessário saber sobre os fundamentos da matemática para extrair alguma consequência para as outras matemáticas.

Se for possível colocar as questões nestes termos, podemos deduzir a terceira característica do pensamento moderno: a infinitude. Se o real é um impasse tributário de uma rede de conceitos, e não uma realidade anterior ao sistema conceitual e contra a qual nós nos chocaríamos; se não podemos falar mais em uma hierarquia de conhecimentos - tal como aquela em que a filosofia tentou se firmar durante um bom tempo: pensamento/empiria, filosofia/ciência mas de um racionalismo regional; então não podemos mais falar de um mundo finito: este é tributário de um pensamento de acumulação, do qual podemos sempre estar mais perto da totalidade anterior do mundo. Ao contrário, o real só aparecerá quando uma nova lógica for posta em funcionamento. Vetor de abstração, dialética abstrato-experiência, e nada de métodos independentes do problema e de sua maneira de colocá-lo. Afinal de contas, não foi assim que Freud fez a psicanálise, saindo da hipnose sugestiva que já apontava as soluções de antemão — mas que não funcionava — para o método da associação livre, no qual, da rede de associações, o sujeito vai formulando tanto o problema que o aflige quanto a maneira de sair dele. Desses impasses podemos pensar a orientação para uma produção positiva que abordaremos a partir de agora tanto nos termos que Dominique Lecourt chama de qualificação desqualificante, e Lacan chama de subversão. 


\section{QUALIFICAÇÃO DESQUALIFICANTE}

O que podemos considerar como qualificação desqualificante?

A expressão qualificação desqualificante foi proposta por Dominique Lecourt (1969, p.40) para expor uma questão que atravessou a epistemologia de Gaston Bachelard: a ruptura que há entre o trabalho científico, seus conceitos e problemas, e o senso comum e a filosofia. A questão incidia principalmente sobre o tema da transmissão de um conceito novo e pode ser colocada da seguinte maneira: os termos que são utilizados em ciência e pelo senso comum e a filosofia são os mesmos. Se esses termos estenografam conceitos distintos devido ao fato de cada um desses campos tratar de um problema específico, é necessário indicar a ruptura entre eles. O mesmo vale para a ruptura que encontramos dentro da própria atividade científica. Pois não podemos deixar de lembrar que as palavras têm uma história, e que se trabalhamos com conceitos, é preciso dar outro sentido que não seja o habitual. Como lembra Lecourt, Bachelard em um primeiro momento se vale de neologismos para pensar as novidades. No entanto, um neologismo não repercute se não for tomado a partir de um movimento que o introduz sistematicamente. E por essa razão é que a partir de determinado momento ele muda de procedimento e passa a se valer da qualificação desqualificante. Em primeiro lugar, é necessário considerar a qualificação desqualificante um procedimento que permite problematizar os conceitos habituais. E não podemos esquecer que colocamos os conceitos em questão por duas razões: a primeira, devido aos impasses que encontramos em sua extensão; a segunda, por ser da característica do Espírito Científico "questionar para saber melhor", ou seja, problematizar um conceito a partir da elaboração de novos conceitos.

Além da problematização dos conceitos, a qualificação desqualificante indica, se a tomarmos em sentido mais restrito, outro uso dos mesmos. Não se trata de uma via meramente crítica, mas a crítica se faz pela produção de novas relações conceituais. Essas novas relações conceituais devem necessariamente marcar ao mesmo tempo quais são os conceitos antigos e como a ruptura com esses conceitos reconfigura um campo de saber. Este novo uso que traça um novo modo de encaminhar as questões e um rearranjo no real é indicado pelo qualificativo que desqualifica o sentido habitual.

Podemos dizer que a partir da qualificação desqualificante temos três consequências: a primeira é que ela permite evitar o empirismo do senso comum que pretende situar a realidade científica como dada. Ora, uma realidade científica, como indica Bachelard, só surge em função de um problema, e um problema não é dado e sim colocado. Isto significa que um objeto é sempre precedido por teorias. Desse modo, não podemos considerar teórica uma pesquisa sem consequências para seu campo específico de problemas. 
A segunda é que o trabalho científico se caracteriza pela problematização mais do que pela busca de soluções. Se a qualificação desqualificante implica necessariamente na problematização, ela implica também em outra noção que aos olhos ingênuos deveria ser evitada na ciência: o erro. A qualificação desqualificante é um processo que coloca em seu centro não a busca pela certeza, mas a busca pelo erro. Pois se a qualificação desqualificante aponta para uma novidade, essa novidade é uma objeção ao conhecimento anterior. Como diz Gaston Bachelard, o que caracteriza o pensamento científico é a perspectiva de erros retificados.

Se há uma busca pelos erros, isso não pode deixar de ter impactos sobre a noção de método. Em primeiro lugar, não podemos mais considerar o método como um procedimento de atingir uma realidade dada; o método é um aparato conceitual que permite construir o objeto científico a partir das retificações dos conhecimentos anteriores. Como diria Bachelard, "uma crise no método é imediatamente uma consciência da reorganização do método" (1977, p.125). Ao que acrescentaríamos: essa reorganização leva necessariamente a uma modificação mesma do objeto. Deixamos aqui o registro do método como sendo aquele da descrição para o registro da produção: “a ciência moderna não é uma ciência de fatos. É uma ciência de efeitos” (1932, p.229); e "ela não se preocupa com o como fenomenológico, e sim com o porquê matemático” (1996, p.8).

Se aliarmos essa noção de que o método é um processo de produção de um objeto - uma objetivação - com a perspectiva de erros retificados que caracteriza o pensamento científico, nós temos então outra visão sobre a questão do método: ele deixa de ser apenas um procedimento de bom encaminhamento, mas se torna propriamente científico se procura o risco de se colocar em questão. "O Espírito Científico vive na estranha esperança de que o método fracasse totalmente" (BACHELARD, 1977, p.124). Estranha esperança para aqueles que pretendem encontrar na ciência mais um meio de responder às suas questões. Como diz Bachelard, "ninguém pode arrogar-se o espírito científico enquanto não estiver seguro, em qualquer momento da vida do pensamento, de reconstruir todo o próprio saber" (1996, p.10).

Ora, essa noção de problematização, de retificação, de construção de um aparelho que busca metodicamente o erro — será que não podemos encontrar isso em psicanálise? Como diz Graciela Brodsky, "o artefato analítico é destinado a obter a falha na engrenagem. Se quiserem, é um dispositivo experimental" (2004, p.45). Não é a partir de uma falha, seja no saber teórico de uma época sobre os problemas psíquicos, seja no saber do sujeito sobre si mesmo? Essa ruptura não ocorre por meio de um procedimento denominado por Lacan de subversão? Vejamos então como a subversão opera em psicanálise, principalmente no que concerne à pesquisa. 


\section{SUBVERSÃO}

Phillipe Julien (2002, p.11) nos lembra que a psicanálise não tem palavras próprias, mas as toma de empréstimo de outras áreas para dar-lhes um sentido em função de suas hipóteses fundamentais, principalmente a de que há pensamentos inconscientes. Ela parte de uma escuta para, a partir daí, fundar um saber teórico. Ora, sabemos desde Lacan que o termo fundação implica uma solidão teórica. Desse modo, esse trabalho de tomar termos de outras disciplinas e, pela escuta, questionar o saber estabelecido, tem um nome em psicanálise: subversão. A subversão é a maneira pela qual a psicanálise faz com que os impasses em relação ao saber sejam ultrapassados por outro modo de considerar os problemas.

Nessa introdução, no entanto, nós temos algumas suposições que devemos tornar claras: a primeira é que uma pesquisa pressupõe um impasse; a segunda é que para sair desses impasses é necessário um ato. Ora, todo ato inaugura um antes e um depois. Ressignifica o passado a partir do momento que se muda de posição. Como diz Gaston Bachelard, a partir do instante que se encontra em um novo momento e configuração de um campo, esse saber novo é o que deveria ter sido pensado, mas esse dever se impõe no só-depois da realização. Da mesma forma, Graciela Brodsky (2004, p.33) diz que a subversão nos aponta para o erro de considerar as coisas como existentes desde sempre.

Mas, o que é a subversão? Recorremos de novo a Brodsky, e ela prossegue dizendo que em psicanálise nós temos a buscar do impasse porque essa é a busca pela prova. "Um caso que desmente a teoria é um caso interessante" (2004, p.43). A subversão só poderá advir a partir do momento em que não temos como nos manter dentro de nossa orientação teórica. Ela deve ser posta sempre à prova. A noção de a orientação metodológica busca o impasse é o que viabiliza a subversão. Como nos lembra Brodsky, Lacan usa o termo subversão contra o termo revolução. Para Lacan, o revolucionário é aquele que retorna ao mesmo ponto, que gira em torno do mesmo eixo. Já a subversão implica que se passe a girar em torno de outro eixo, que se passe a considerar os problemas a partir de outros princípios. Na subversão, há uma transformação que vem em decorrência de um impasse.

Mas como obter essa transformação? Ora, na ideia de transformação está implícita a noção de novidade. Uma pesquisa pode prescindir de novidade? Essa questão tem vários matizes. Podemos evocar a resposta de um lógico a Quine, contada por Miller sobre os avanços da lógica: “esses são seus progressos em Lógica nos últimos vinte e cinco anos, senhor Quine, mas certamente não são os progressos da lógica” (MILLER, 2002, p.50). Aqui temos o novo para o pesquisador, mas não necessariamente para o campo de problemas. No caso do discurso universitário brasileiro, essa novidade para o pesquisador é importante, pois muitas vezes é na pesquisa que ele terá acesso a um saber que, mesmo já 
sedimentado, ainda é pouco divulgado. E como, no caso brasileiro, a pesquisa em nível de pós-graduação é parte integrante da formação de novos professores, não devemos ser tão severos como o lógico foi com Quine.

No entanto, ao pensar sobre o novo para o campo de problemas, podemos dizer que algo de novo só surge sob o fundo de repetição. Miller chega mesmo afirmar que é sob o fundo de repetição que se pode elaborar as condições da novidade. Até mesmo um neologismo, para surtir efeitos, deve vir sob a marca da repetição. Assim, a novidade está mais ligada à subversão dos termos do que à criação intempestiva de novos termos. O novo se impõe com consequências mediante a subversão, mediante um termo que não gira mais em torno do mesmo eixo. Ou como diz Miller, a “subversão é da ordem de um significante que escapa ao código, criando desse modo o sentido. É o sentido que está na diferença. Não se trata de ser uma exceção, mas de subversão da regra” (1999, p.37).

Podemos dar três exemplos já considerados clássicos em psicanálise: o primeiro é a revisão efetuada por Freud em sua teoria do aparelho psíquico quando o conceito de inconsciente corria o risco de deixar de ser operativo, uma vez que até mesmo a instância que deveria se opor aos pensamentos inconscientes - o eu - comporta uma dimensão inconsciente. Esse impasse se deu também pela dificuldade de Freud em considerar determinados fenômenos que só se tornaram problemáticos como um limite, um impasse que desafiava a psicanálise: as neuroses traumáticas e a questão das psicoses. Mas é preciso considerar que esses fenômenos só podem aparecer problemáticos sob o fundo de conceitos que articulavam a prática psicanalítica até então.

O segundo exemplo é relativo ao conceito de sexualidade infantil. Essa conjugação de termos indica já que a sexualidade da qual se trata não pode ser reduzida à genitalidade, ou não haveria a necessidade de designá-la como infantil; por outro lado, o infantil também é questionado, uma vez que não permite traçar, em relação à sexualidade, um mundo que fosse adulto, ou seja, determinar um modo privilegiado da relação sexual em que todos os outros estivessem excluídos. Não é gratuito que os conceitos relacionados à sexualidade infantil sejam o de perverso-polimorfo e o de pulsão que não tem objeto pré-determinado. Lacan acaba reduzindo toda essa questão ao seu aforismo "não há relação sexual".

O terceiro exemplo encontrado na teoria psicanalítica que leva a uma reformulação devido aos impasses na extensão de um conceito é a utilização de sessões de tempo variável proposta por Lacan. Essa proposta não se dá por capricho ou por comodidade, como afirmam algumas pessoas. Deu-se por uma dificuldade em que o tempo de sessão invariável não permitia contornar: as resistências de neuróticos obsessivos. Isso, por um lado. Por outro, a sessão de tempo fixo não era de acordo com a definição de inconsciente que, segundo Freud, não conhece o tempo. Desse modo, nós temos também uma qualificação — o tempo variável 
- que devido a um impasse — as resistências — desqualifica uma posição a partir de uma escansão na teoria - a sessão de tempo fixo.

Assim, concluímos com o que Graciela Brodsky articula em torno do tema do ato analítico: pois encontramos lá justamente a dimensão em que o ato se caracteriza por um salto, por uma decisão que vai além das premissas. Creio que essa é uma boa orientação metodológica, uma vez que nos encaminha para seguir os impasses que surgem, levando-os ao limite. Não podemos esquecer que um impasse, para citarmos a definição de Koyré tomada por Miller, aponta sempre para a realização de um impossível (MILLER, 2000b, p.76).

\section{PESQUISA}

Postos os temas da qualificação desqualificante e da subversão psicanalítica, podemos considerar que, se pretendemos pensar em uma metodologia ou método de pesquisa em psicanálise, esse não pode deixar de comportar a dimensão de ato que subverte e desqualifica a noção em questão. Acreditamos que o método, ao ser pensado pela psicanálise, acabe sendo desqualificado de sua aura de ponto infenso à dúvida, de fiador da legitimidade de uma pesquisa. Que método há para a pesquisa em psicanálise? Se nos ativermos à clínica psicanalítica, podemos dizer que, se método há, ele é a própria clínica: práxis que se estrutura não em torno de um saber, mas de um não-saber. Essa noção de não-saber é considerada por Lacan também a partir da douta ignorância: uma ignorância conquistada metodicamente seja a partir do estranhamento advindo da própria análise — trabalho de transferência — seja a partir do estranhamento em relação aos ditames da civilização que configura o trabalho teórico — transferência de trabalho. O saber produzido tanto em análise quanto a partir de uma psicanálise se constitui a partir dessa posição estudada de um não-saber que estrutura tanto o dispositivo analítico quanto o ato analítico. Sem a operatividade do não-saber, não é possível haver escuta analítica.

Utilizamos até aqui um termo que não foi questionado: pesquisa. O que entender pelo termo pesquisa? Em primeiro lugar não podemos nos enganar que com o termo pesquisa estamos necessariamente às voltas com a ciência. Lacan (1964/1985), ao se colocar a questão de saber se a psicanálise é uma ciência ou não, nos chama atenção para três termos os quais ele questiona que basta mencioná-los para se estar na ciência. Ele nos aponta que se para uma práxis ser científica demanda um objeto, não podemos considerar esse objeto como dado desde sempre e que caberia ao cientista descobri-lo, mas ao contrário: esse objeto muda de acordo com a maneira pela qual ele é abordado. Como diria Bachelard, o objeto é fabricado, e não dado (1996, p.18). Em segundo lugar, não podemos dizer que uma práxis é uma experiência para ser considerada científica, pois há outras experiências que não são científicas, o que não significa que 
não sejam reais. Ele evoca o exemplo da mística. É o mesmo exemplo que Jean Ullmo (1967) fornece ao especificar que a ciência é reprodutível, ao contrário da mística. Podemos mesmo fazer aqui a distinção feita por Koyré (1991) entre experiência não reprodutível e que demanda outro modo de transmissão, e outros experimentos, em que há a possibilidade de transmissão integral.

Mas Lacan se dedica a fazer uma crítica maior ao termo pesquisa. O psicanalista começa dizendo que desse termo há que se desconfiar, pois, ao se associar ao registro de uma busca, aproxima-se muito mais ao discurso religioso do que ao científico - religioso no sentido de que se busca tão somente aquilo que já se encontrou, uma busca orientada pelo já achado. Desse modo, a pesquisa, longe de ser compatível ao Espírito Científico, é antinômica a ele. Pois o que especifica o Espírito Científico, como aponta Gaston Bachelard, é justamente a disposição de pôr em questão todo o saber. Isto não significa a simples refutação de uma hipótese, mantendo-se o método e o arcabouço teórico; trata-se de uma reestruturação radical do saber. É manter a pesquisa no que podemos chamar de tempo de compreender, no qual nenhuma consequência é extraída, e, por mais produções que se tenha, não há a realização de um impossível.

Se, por um lado, Lacan comenta a sua desconfiança em relação ao termo pesquisa como sendo da ordem da busca, ele por outro, aponta para orientação diferente, que não é mais do tempo infinito da compreensão e nem se trata de uma pesquisa complacente com os princípios já dispostos. Lacan diz que, à maneira de Picasso, não procura, acha. Achar não significa necessariamente topar com algo que já está aí, mas ao contrário: achar é da ordem do ato, do inesperado, ocasião em que a conclusão se impõe e implica um corte com o saber que estava norteando a teoria em um momento anterior. Achar, aqui, é comparável com a fundar, no sentido de que fundar um campo implica necessariamente uma solidão. É o que encontramos em Freud, que funda um novo campo que demanda novos conceitos a partir de sua hipótese inaugural: a de que há pensamento inconsciente. Só podemos falar de inconsciente a partir do ato de Freud que rompe com o saber de então, isto é, a partir do momento em que ele o encontra, e nunca antes. Se fazemos análise do que vem antes de Freud nos valendo do termo inconsciente, é porque ele implica uma reorganização do saber.

Se tomarmos as definições de Freud sobre pesquisa, podemos ver o quanto Lacan segue aqui a via aberta pela descoberta do inconsciente. Freud (1922/1996, p.253) diz que a psicanálise é tanto um método de pesquisa como de tratamento. Mas há mais nessa definição: de que a pesquisa é etiológica, ou seja: uma pesquisa que permita descobrir as causas do sofrimento do sujeito. Em psicanálise, como lembra Jacques-Alain Miller, uma vez descobertas as causas, cessa-se o efeito, ou seja, uma vez a causa trazida à luz, ela cessa de produzir como efeito 
os sintomas. Freud mesmo já indicava isso ao dizer que o inconsciente trabalhava no escuro para fazer com que aquilo que foi afastado da consciência por uma defesa retorna transformado (1915/1996). No entanto, em relação a quê se articula a causa em psicanálise? Como lembra Lacan ainda em seu seminário sobre os conceitos fundamentais da psicanálise, só há causa para o que tropeça, o que falha, o que faz furo. Furo em um saber, falha em relação às disposições de um saber que se mostra insatisfatório. Sem esse tropeço, não há busca pela causa. Sem esse tropeço, não há impasses que façam com que o sujeito coloque em questão os saberes que o constituíram até então. Desse modo, nós temos uma articulação entre método de investigação que gira em torno de um impasse, de um não-saber, e o método de tratamento de sujeito que gira em torno de um tropeço que não se integra às coordenadas simbólicas, uma articulação em torno do conceito de causa. Pois do mesmo modo que em uma atividade científica é o impasse que leva a um questionamento das leis e dos princípios que fundamentam sua práxis, nós também temos, em relação ao sujeito, um ponto de tropeço no qual ele coloca em causa sua relação com o saber.

Recebido em: 28/4/2008. Aprovado em 4/12/2008.

\section{REFERÊNCIAS}

BACHELARD, G. (2004) Ensaio sobre o conhecimento aproximado. Rio de Janeiro: Contraponto.

. (1996) A formação do espírito científico. Rio de Janeiro: Contraponto.

(1977) O racionalismo aplicado. Rio de Janeiro: Jorge Zahar.

(1932) Le pluralisme cohérent de la chimie moderne. Paris: J.Vrin.

BLANCHÉ, R. (1983) A ciência actual e o racionalismo. Lisboa: Res Editora.

BRODSKY, G. (2004) Short Story. Rio de Janeiro: Contracapa.

CANGUILHEM, G. Dialectique et philosophie du nom chez Gaston Bachelard, in Études d'histoire et de philosophie das ciences. Paris: J.Vrin, 1975.

FREUD, S. (1922). Dois verbetes de Enciclopédia, in

Edição standard das obras completas de Sigmund Freud, vol. XVIII. p.253-280, Rio de Janeiro: Imago. (1915). O recalque, in (1996) Edição standard das obras completas de Sigmund Freud, vol. XIV. p.253-280, Rio de Janeiro: Imago.

KOYRÉ, A. (1991) Galileu e Platão, in . Estudos de história do pensamento científico, Rio de Janeiro: Forense Universitária. 
LACAN, J. (1966) De nossos antecedentes, in Escritos. Rio de Janeiro: Jorge Zahar, 1998.

(1964) O Seminário, Livro 11: Os quatro conceitos fundamentais da psicanálise. Rio de Janeiro: Jorge Zahar, 1985.

LECOURT, D. (1969) L'épistemologie historique de Gaston Bachelard. Paris: J.Vrin.

MILLER, J-A.(1998) Discurso do método psicanalítico, in Lacan elucidado. Rio de Janeiro: Jorge Zahar.

(2000a) Sobre o transfinito, in Phoenix: revista da delegação Paraná da escola brasileira de psicanálise, $\mathrm{n}^{\circ} 1$. . (2002) Lettres à l'opinion eclairée. Paris: Seuil. (1996) Perspectivas do seminário 5 de Lacan. Rio de Janeiro: Jorge Zahar.

(2000b) A erótica do tempo. Rio de Janeiro: Escola Brasileira de Psicanálise.

MILNER, J-C. (1996) A obra clara. Rio de Janeiro: Jorge Zahar.

ULlMO, Jean. (1967) O pensamento científico moderno. Coimbra: Coimbra Editora.

Roberto Calazans

calazans@ufsj.edu.br

Tiago Iwasawa Neves

Tiagoiwasawa@yahoo.com.br 